\title{
Dynamic Modeling and Control of DFIG for Wind Energy Conversion System Using Feedback Linearization
}

\author{
Ghulam Sarwar Kaloi ${ }^{\dagger}$, Jie Wang* and Mazhar Hussain Baloch**
}

\begin{abstract}
This paper presents a dynamic modeling and control of doubly fed induction-generator (DFIG) based variable speed wind-turbine. The dynamic model of DFIG is incorporated with all system components which provide simple design and controls. The penetration of wind power is increasing into electrical networks, which necessitates more comprehensive studies to recognize the interaction between the wind farms and the power grid. This paper presents the dynamic model of a DFIG based wind turbine connected to the grid system in the $d q$-synchronous reference frame. In this article, the feedback linearization method has proposed a controller in order to reduce the oscillation and stabilize the wind turbine system parameters based on feedback linearization concepts. Based on the nonlinear control system, the proposed approach is applied to the rotor side converter and grid side converter. The damping of the DFIG is improved in transient response. In addition, the oscillation of the stator current and DC link voltage during the generator voltage dip are reduced. To the best of author's knowledge, the proposed control outcomes compared with conventional controller verified the effectiveness, having better performance through simulation tool Matlab.
\end{abstract}

Keywords: Doubly fed induction generator, Dynamic modeling, Feedback linearization control, Transient stability, Wind turbine generator

\section{Introduction}

The depleting fossil fuels and global warming are much concerned with the environment. The renewable energy sources have emerged as a new model to meet the energy requirements of our society. In recent years, the production of electricity from hydropower, solar, wind and geothermal energy, tides, waves and biomass energy sources have gained much attention. Wind energy will play a significant role in the energy industry in the future. The rapid development of wind power generation technology has shown that it has gained global attention [1]. The application of DFIGs in modern energy systems has many advantages, such as, variable speed operation, active and reactive power capabilities.

In DFIG, connection of stator is done to the power grid directly, while bi-directional converter is used for the rotor connection to control active and reactive power between the stator and AC supply network [2]. Rotor current disorients the vector control technique into active and reactive power components based on wind turbine technology. Rotor current controllers control these components through the rectification of rotor current excitation voltage

$\dagger$ Corresponding Author: School of Electronic Information and Electrical Engineering, Shanghai Jiao Tong University, P R China. (ghulamsarwar@sjtu.edu.cn)

* School of Electronic Information and Electrical Engineering, Shanghai Jiao Tong University, P R China. (jiewangxh@sjtu.edu.cn)

** Dept. of Electrical Electrical Engineering, Mehran UET, SZAB Compus Khair Pur Mir's Pakistan, Pakistan. (embaloch@sjtu.edu.cn) Received: February 22, 2016; Accepted: May 10, 2016
$[3,4]$. The challenges must be attempted for the operation of wind farms on a large scale. A nonlinear feedback controller was developed by the electromechanical model through coupling of DFIG and wind turbines. The greater use of renewable energy is enforced globally due to energy sustainability and environmental issues of traditional power plants $[5,6]$. Many technical challenges associated with utilization in the electric power systems are power quality, reliability and protection.

Wind energy gains the significant attention due to a renewable energy source and an economical as compared to conventional power sources. The large variations in natural wind cause irregularities in wind energy. The wind energy conversion system faces significant challenges due to large variation in energy as compared to conventional energy sources [7-9]. The fluctuation of out power causes frequency deviation which implies to the instability of system with high penetration. Wind energy conversion systems are considered as harmful loads due to the high fluctuation in output power [10,11].

The inheritance non-linearity in wind power plants due to dynamics model of DFIG depends on wind speed and electromagnetic torque rotation. It is a nonlinear function of the stator and the rotor current. The careful tuning of the rotor current controller must be ensured for the stability of closed loop system and sufficient transient response within the operating range [12-14]. Furthermore, the field oriented control requires the estimation or measurement of flux. In order to meet the demands of active and reactive power, it is required to move up and down to generating units [15]. 
The associated maintenance unit cost of such maneuvering actions must be minimum, the required wind generators by the network for riding through the ability of external AC perturbation. The suggestion of limiting the over current of the generator by monitoring through the network fault was given by an advanced control under the conditions of unbalanced voltage, and improves the voltage network perturbation $[16,17]$.

The essential requirement of addressing the issues of relaying protection of a power grid with DFIGs is to study the fault current characteristics of DFIG. These conditions are different from the conventional synchronous generator. The fault current characteristics of DFIG (transient components and damping time constants) are different under considered conditions. So, it necessitates the study of characteristics of DFIG separately for given conditions $[18,19]$. Many studies are proposed for fault condition. Whereas, analysis of fault current characteristics of the DFIG is very difficult due to complicated result of dynamic response of AC / DC / AC converter under fault condition. The fault current of DFIG was studied under the condition that excitation current will be constant before and after the fault occurrence $[20,21]$.

The study based on aforementioned assumption is not suitable for practical systems. Since, another qualitative work was done for fault current characteristics while considering the dynamic response of the rotor side convertor (RSC) and grid side convertor (GSC). The work presented in that research cannot meet the requirement of the study of relaying protection. In order to fill this gap, the theoretical analysis method is proposed for the fault current characteristic of DFIG under non severe condition. However, the rotor windings are still excited; the dynamic response has a large influence on the characteristics of the stator fault current. It is requires that wind turbines must be connected and play an active role in the stability of the system during and after the disturbances or fault. By this approach, other system dynamics can be deteriorating. The disturbance in the field is removed from the behavior of the turbine generator in the field of transient studies $[22,23]$.

In order to meet the requirements of the DFIG through the voltage dip, the limit of the rotor side converter can increase the stator fault current and DC link voltage. The theoretical basis of the analysis was established, and the DFIG transient behavior is improved after removal of the disturbance in the study. The nonlinear control design used the dynamic model analysis to resolve the nature of instability and improvement in the performance of the generator.

\section{Wind Turbine Model}

The captured mechanical power by a wind turbine is given as follows:

$$
P_{m}=\frac{1}{2} C_{p}(\lambda, \beta) \rho R_{T}^{2} \pi V_{\omega}^{3},
$$

where $\rho$ representsthe air density, $R_{T}$ the wind turbine radius, $V_{w}$ the wind speed and $C_{p}$ the wind turbine power coefficient. The $C_{p}$ is calculated by

$$
\begin{aligned}
C_{p}(\lambda, \beta) & =0.22\left(\frac{116}{\lambda_{i}}-0.4 \beta-5\right) e^{\frac{-12.5}{\lambda_{i}}}, \\
\frac{1}{\lambda_{i}} & =\frac{1}{\lambda+0.08 \beta}-\frac{0.035}{\beta^{3}+1},
\end{aligned}
$$

where $\beta$ represent the blade pitch angle and $\lambda$ represent the tip speed ratio as described [18].

$$
\lambda_{\text {opt }}=\frac{\omega_{r} R_{T}}{V_{w}},
$$

Owing to the presence of a gearbox with the gear ratio $n_{g}$, the dynamic model wind turbine rotational speed $\omega_{\text {rot }}$ is associated to the rotor speed $\omega_{r}$.

$$
\omega_{r}=n_{g} \omega_{r o t} .
$$

The exact dynamic model of the torque equation of the generator is given by,

$$
T_{m}=\frac{P_{m}}{\omega_{r}}
$$

where, $T_{m}$ represents the rotor torque, $\omega_{r}$ represent the wind turbine speed, it is a measure of the ratio of wind power turbines. Power coefficient is a function of wind turbine speed. $C_{p}$ is 0.59 the theoretical limit, but practical range is $0.2-0.4$ [24]. For the optimal tip speed ratio $\lambda_{\text {opt }}$, (4) and (5) provide the optimal speed of the generator as

$$
\omega_{r}^{o p t}=\frac{\lambda_{o p t} n_{g}}{R_{T}} V_{w}
$$

Which corresponds to the most extreme extraction of wind energy $P_{m}^{\max }$, at that point in the determination of the rotor torque of the generator can be determined as

$$
T_{m}^{o p t}=\frac{1}{2} \frac{\rho \pi R_{T}^{5} C_{p}^{o p t}}{\lambda_{o p t}^{3}} \omega_{r}^{o p t}
$$

It is obvious that the wind turbine to turn with ideal rotational speed and with the ideal torque of the nonlinear dynamic model of the doubly fed induction generator act as the external input of the mechanical part of the system. 


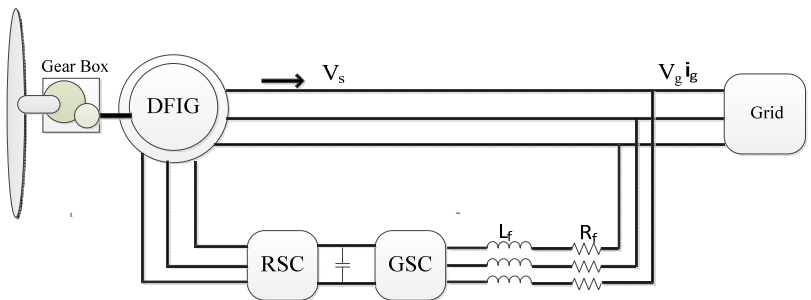

Fig. 1. Schematic diagram of wind energy based on DFIG system

\section{Nonlinear Dynamic Modeling of DFIG Wind Energy System.}

The power convertor of the wind turbine generator that contains the rotor converter to control the generator speed and grid convertor to inject reactive power in the grid, the grid side converter components of the real and reactive power as shown in Fig. 1. The instantaneous power can be defined as follows [25]:

$$
\begin{aligned}
\tilde{S}_{s} & =\frac{3}{2} \dot{V}_{s}^{*} \stackrel{I}{s}^{*} \\
S_{g} & =\frac{3}{2} \dot{V}_{s} I_{g},
\end{aligned}
$$

where $\tilde{S}_{s}$ is the power of the stator, $\tilde{S}_{g}$ is the power of the grid and "*" represents the conjugate of $I_{s}$. Resolve the Eq. (9) and Eq. (10), we have

$$
\begin{gathered}
I_{g}=\frac{2}{3}\left(\frac{S_{g}}{V_{s}}\right), \\
I_{s}=-\frac{2}{3}\left(\frac{S_{s}}{V_{s}}\right)^{*} .
\end{gathered}
$$

It is observed that the negative sign in Eq. (12), complies with direction the stator power flow on Fig. (1), the nonlinear dynamic model of the doubly induction generator is normally described by the toque and voltage equation. A wind turbine dynamic model is developed by the real and reactive power.

\subsection{DFIG wind turbine system modeling in the $d q$ reference frame}

The nonlinear dynamic model of the doubly fed induction generator represents the flux and the voltage equation can be summarized as:

$$
\begin{aligned}
& V_{s}=R_{s} I_{s}+j \omega_{e} \Psi_{s}+\frac{d \Psi_{s}}{d t} \\
& V_{r}=R_{r} I_{s}+j \omega_{s l} \Psi_{r}+\frac{d \Psi_{r}}{d t}
\end{aligned}
$$

$$
\begin{aligned}
& \Psi_{s}=l_{s} I_{s}+l_{m} I_{r} ; \\
& \Psi_{r}=l_{m} I_{s}+l_{r} I_{r},
\end{aligned}
$$

where, $R_{s}$ and $R_{r}$ are the stator and rotor resistance, $l_{s}$ and $l_{r}$ are the stator and rotor inductance while $l_{m}$ representing the mutual inductance, $\omega_{e}$ is the synchronous (stator) frequency. Subscript, $S$ and $r$

Indicate the stator and rotor variables. In addition $V_{s}, I_{s}$ and $\Psi_{s}$ represents the voltage, current and stator flux, $V_{r}$, $I_{r}$ and $\Psi_{r}$ are represent the rotor voltage, current and flux vectors.

The complex quantity of current, voltage and flux vector can be described as follows:

$$
\begin{aligned}
& \Psi_{s}=\Psi_{d s}+j \Psi_{q s}, \Psi_{r}=\Psi_{d r}+j \Psi_{q r}, I_{s}=I_{d s}+j I_{q s} \\
& I_{r}=I_{d r}+j I_{q r}, \quad \omega_{s l}=\omega_{e}+\omega_{r}, \quad V_{s}=V_{d s}+j V_{q s}
\end{aligned}
$$

The dynamic model of the rotor current and flux are originated from (15) and (16), given by:

$$
I_{r}=\frac{\Psi_{s}-l_{s} I_{s}}{l_{m}}, \quad \Psi_{r}=\frac{l_{r}}{l_{m}}\left(\Psi_{s}-l_{s}^{\prime} I_{s}\right),
$$

By substituting for $I_{r}$ and $\Psi_{r}$ from (18) and (16) into (14), then solving (13) and (14) for $\dot{\zeta}_{s d}$ and $\dot{\zeta}_{s q}$.

$$
\begin{aligned}
& \frac{d}{d t} \zeta_{d s}=C_{d 1} V_{d s}-C_{q 1} V_{q s}+C_{d 2} \Psi_{d s}-C_{q 2} \Psi_{q s}+C_{d 3} \zeta_{d s} \\
& +C_{q 3} \zeta_{q s}+C_{d 4} V_{d r}-C_{q 4} V_{q r} \\
& \frac{d}{d t} \zeta_{q s}=-C_{q 1} V_{d s}-C_{d 1} V_{q s}-C_{q 2} \Psi_{d s}-C_{d 2} \Psi_{q s}-C_{q 3} \zeta_{d s} \\
& +C_{d 3} \zeta_{q s}-C_{q 4} V_{d r}-C_{d 4} V_{d r}
\end{aligned}
$$

where, $\zeta_{d s}$ represent the stator current in $\mathrm{d}$ axis, $\zeta_{q s}$ represent the stator current in $\mathrm{q}$ axis. The equation of the stator flux can be described by substituting for $I_{s}$ from (12) into (13) for $\dot{\Psi}_{s d}$ and $\dot{\Psi}_{s q}$

$$
\begin{aligned}
& \frac{d}{d t} \Psi_{d s}=V_{d s}+b_{d 1} \Psi_{d s}+b_{q 1} \Psi_{q s}+b_{d 2} \zeta_{d s}+b_{q 2} \zeta_{q s} \\
& \frac{d}{d t} \Psi_{q s}=V_{q s}+b_{q 1} \Psi_{q s}+b_{d 1} \Psi_{q s}+b_{q 2} \zeta_{d s}-b_{d 2} \zeta_{q s}
\end{aligned}
$$

The nonlinear dynamic model of the DFIG wind turbine equation of the rotor and torque model is given as follows:

$$
\begin{aligned}
& \frac{d}{d t} \omega_{r}=\frac{p}{j}\left(T_{e}-T_{m}\right), \\
& T_{e}=-P \operatorname{Im}\left(\Psi_{s} \zeta_{s}\right),
\end{aligned}
$$

By substituting (22) into (21), the following equation can be obtained: 


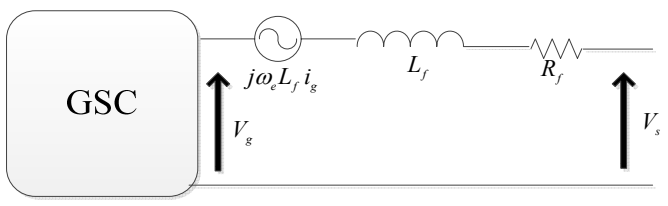

Fig. 2. Equivalent circuit of the grid side convertor

$$
\frac{d}{d t} \omega_{r}=\frac{p^{2}}{j} \operatorname{Im}\left(\Psi_{s} \zeta_{s}\right)-\frac{p}{j} T_{m}
$$

\subsection{Grid-side convertor and filter model}

The grid sides filter convertor shows in Fig. 2. The $d q$ model of grid side convertor and the filter is given as follows:

$$
V_{s}=V_{g}+l_{f} \frac{d i_{g}}{d t}+j \omega_{e} l_{f} I_{g}+R_{f} I_{g}
$$

where, $V_{g}$ represent the grid voltage, $I_{g}$ represent the grid current, $l_{f}$ represent the filter inductance and $R_{f}$ represent the filter resistance.

Now taking equivalent real power of the dynamic model of the DFIG, this can be obtained in the DC link model at the DC converter node as follows:

$$
V_{d c}(t) I_{d c}(t)=P_{g}(t)-P_{\mathrm{r}}(t)-P_{l o s s}(t),
$$

where $P_{\mathrm{r}}(t)$ represent active power of the rotor, $P_{g}(t)$ represent the grid power and $P_{\text {loss }}$ represent the power losses, including the converter switching losses and the copper losses. The apparent power $S_{r}$ delivered to the rotor.

$$
S_{r}=1.5 V_{r} \stackrel{*}{I_{r}}
$$

substituting $i_{r}$ from (18) into (26), we can obtain $S_{r}$ as follows:

$$
\tilde{S}_{r}=1.5 \frac{1}{l_{m}} \stackrel{*}{\Psi}_{s} V_{r}+\frac{l_{s}}{l_{m}} \zeta_{s} V_{r}
$$

The DC link model voltage can be obtained by substituting (27) into (25) as follows:

$$
\frac{d}{d t} V_{d c}=\frac{1}{C V_{d c}}\left\{P_{g}-\operatorname{Re}\left(1.5 \frac{1}{l_{m}} \Psi_{s}^{*}+\frac{l_{s}}{l_{m}} \zeta_{s}\right) V_{r}\right\} .
$$

The nonlinear dynamic model of the doubly fed induction generator represents the stator voltage equation can be summarized as:

$$
\frac{d}{d t} V_{s}=\dot{V}_{l}-\left(R_{l}+j \omega_{l} l_{l}\right)\left\{\left(\frac{-2 S_{s}}{3 V_{s}}\right)^{*}-\left(\frac{2 S_{g}}{3 V_{s}}\right)^{*}\right\},
$$

By resolving the (29), the following equation can be obtained:

$$
P_{g}=\mathrm{R}_{\mathrm{e}}\left\{\frac{1}{2 \dot{Z}_{L}}\left(V_{s} \stackrel{V}{L}^{*}-V^{2}\right)\right\} S_{s},
$$

By substituting (30) into (28), the following equation can be obtained:

$$
\begin{aligned}
& \frac{d}{d t} V_{d c}=\frac{2}{C}\left\{\frac { 1 } { 2 | Z _ { L } | ^ { 2 } } \left(V_{d L} Z_{d L} V_{d s}+V_{q L} Z_{d L} V_{q s}-V_{q L} Z_{q L} V_{d s}\right.\right. \\
& \left.+V_{d L} Z_{q L} V_{q s}-Z_{d L} V_{d s}^{2}+Z_{d L} V_{q s}{ }^{2}-2 V_{d s} V_{q s} Z_{q L}\right)-\left(V_{d s} \zeta_{d s}-V_{q s} \zeta_{q s}\right) \\
& \left.-\left(1.5 \frac{1}{l_{m}} \Psi_{d s}+\frac{l_{s}}{l_{m}} \zeta_{d s}\right) V_{d r}-\left(1.5 \frac{1}{L_{m}} \Psi_{q s}-\frac{l s}{l_{m}} \zeta_{q s}\right) V_{q r}\right\}
\end{aligned}
$$

By substituting (24) into (29), the following equation of the stator voltages can be obtained:

$$
\begin{aligned}
& \frac{d}{d t} V_{d s}=a_{d 1} V_{d s}-a_{q 1} V_{q s}+a_{d 2} \Psi_{d s}-a_{q 2} \Psi_{q s}+a_{d 3} \zeta_{d s} \\
& +a_{q 3} \zeta_{q s}+a_{d 5} V_{d r}-a_{q 5} V_{q r}+\bar{V}_{d g} \\
& \frac{d}{d t} V_{q s}=a_{q 1} V_{d s}+a_{d 1} V_{q s}+a_{q 2} \Psi_{d s}+a_{d 2} \Psi_{q s}+a_{q 3} \zeta_{d s} \\
& -a_{d 3} \zeta_{q s}+a_{q 5} V_{d r}+a_{d 5} V_{q r}-\bar{V}_{q g}
\end{aligned}
$$

Substituting (20a)-(20b) into (13) and (13) into (9), the following equations can be obtained:

$$
\begin{aligned}
& \frac{d}{d t} p_{s}=V_{d s} \zeta_{q s}-V_{q s} \zeta_{d s}-j_{3} \Psi_{d s} \zeta_{q s}-\Psi_{q s} \zeta_{d s}+j_{4} \zeta_{d s}^{2}+j_{4} \zeta_{q s}^{2} \\
& \frac{d}{d t} q_{s}=V_{d s} \zeta_{q s}+V_{q s} \zeta_{d s}+j_{3} \Psi_{d s} \zeta_{d s}-j_{3} \Psi_{q s} \zeta_{q s}
\end{aligned}
$$

\section{Proposed Controller Design for a DFIG Wind Turbine Generator}

The transient stability under distinctive conditions is dominated by the conventional synchronous generators. Since discontinuous renewable energy is being existed in the large scale of the entrance, for instance, the stability of the power system transient is affected by wind power and compared consequences, in this way they need to be studied sufficiently.

Stator voltage and current of the wind turbine used the feedback linearization control strategy with a doubly fed induction generator. The DFIG input parameters are controlled for the $V_{d r}, V_{q r}, \bar{V}_{g d}$ and $\bar{V}_{g q}$ in $d q$ reference structure. In proposed work, the prime objective is to minimize the voltage network perturbation, under normal 
operating conditions. The objective of the controller design method is used to get better results of the wind energy alteration system in order to sustain voltage of the wind turbine, design structure deal with stability, the interruption elimination besides the unaccounted and suspicions dynamics. The DFIG wind turbine system is being elected by control parameters. They are proposed to be integrated with the feedback controller. The system is executed in Matlab/Simulink environment. The dynamic of the DFIG system is verified by the feedback linearization method. The controller is useful to pick up the stability of the system with interruptions [26, 27]. The over current is minimized by the feedback linearization method in order to get a better result of the system, which can be employed to sense the RSC and GSC current and to decrease the transient response of the system. The selected controller makes it possible to get desired results inclusive of the stator current.

The proposed system state variables are given as follows:

$$
x=\left[\begin{array}{llllll}
V_{d s} & V_{q s} & \Psi_{d s} & \Psi_{q s} & \zeta_{d s} & \zeta_{q s}
\end{array}\right]^{T} .
$$

The dynamic model of the doubly fed induction generator is given in the (19a)-(20b) and (32a)-(32b) which is summarized as:

$$
\dot{x}=A x+B_{1} U_{1}+B_{2} U_{2}
$$

where

$$
\begin{aligned}
& A^{T}=\left[\begin{array}{cccccc}
a_{d 1} & a_{q 1} & 1 & 0 & -C_{d 1} & -C_{q 1} \\
-a_{q 1} & a_{d 1} & 0 & 1 & -C_{q 1} & -C_{d 1} \\
a_{d 2} & a_{q 2} & b_{d 2} & b_{q 2} & C_{d 2} & -C_{q 2} \\
-a_{q 2} & a_{d 2} & -b_{q 1} & b_{d 1} & -C_{q 2} & -C_{d 2} \\
a_{d 3} & a_{q 3} & b_{d 2} & b_{q 2} & C_{d 3} & -C_{q 3} \\
a_{q 3} & -a_{d 3} & b_{q 2} & b_{d 2} & C_{q 3} & C_{d 3}
\end{array}\right], \\
& B_{1}=\left[\begin{array}{cc}
a_{5 d} & -a_{5 q} \\
a_{5 q} & a_{5 d} \\
0 & 0 \\
0 & 0 \\
C_{4 d} & -C_{4 q} \\
-C_{4 q} & -C_{4 d}
\end{array}\right], \quad U_{2}=\left[\begin{array}{l}
\bar{V}_{d g} \\
\bar{V}_{q g}
\end{array}\right] \\
& B_{2}^{T}=\left[\begin{array}{llllll}
1 & 0 & 0 & 0 & 0 & 0 \\
0 & 1 & 0 & 0 & 0 & 0
\end{array}\right], U_{1}=\left[\begin{array}{c}
V_{d r} \\
V_{q r}
\end{array}\right] \text {. }
\end{aligned}
$$

As mentioned above the stator voltage is employed through feedback linearization control strategy and the wind turbine system of DFIG to control the current. For the rotor-side converter which controls the stator voltage independently via $V_{d r}, V_{q r}, \bar{V}_{d g}$ and $\bar{V}_{q g}$ respectively, Controlling the current to keep it within rotor speeds $\omega_{r}$ achieves the voltage control, the DC link voltage, $\zeta_{d s}$ and $\zeta_{q s}$ are controlled independently via $V_{d r}$ and $V_{q r}$, respectively. They are forwarded to the pulse width

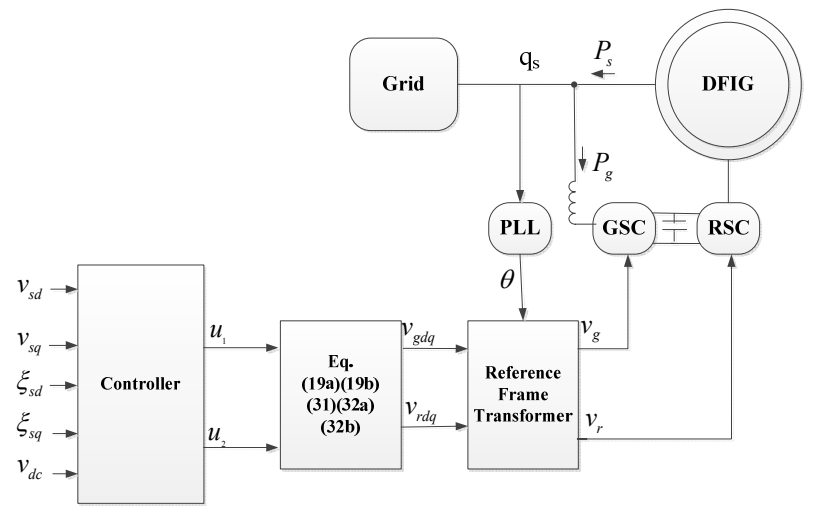

Fig. 3. The study system of the nonlinear dynamic model of the DFIG

modulation (PWM) to generate insulated gate bipolar transistor (IGBT) gate control signal $V_{r}$ derive the RSC and $V_{g}$ derive the grid side converter. Oscillations of the system will be reduced to use of the control signal after the interruption is removed or grid fault is improved. It is easy to apply the voltage $V_{r}$ and $V_{g}$ as input signals of the feedback linearization control. The angular velocity $\omega_{r}$ and fluxes are implemented in steady state, under all circumstances easy to measure; DC link study is equivalent to the stable system by the normal operation of the wind turbine, the steady state systems are the balanced the DC link voltage. Now take the following enhanced model.

Again, we conclude (23), (31), (33) and (34) as follows:

$$
\begin{gathered}
\frac{d}{d t} \omega_{r}=x^{T} \tilde{C} x+\tilde{C}_{o}, \\
\frac{d}{d t} V_{d c}^{2}=x^{T} F_{1} x+F_{2} x+x^{T} F_{3} U_{1}, \\
\frac{d}{d t} p_{s}=x F_{3} x^{T} \\
\frac{d}{d t} q_{s}=x F_{4} x^{T}
\end{gathered}
$$

where

$$
\begin{gathered}
C_{o}=\left[\begin{array}{c}
-\frac{P T_{m}}{J} \\
0 \\
0 \\
0 \\
0 \\
0
\end{array}\right], \tilde{C}=\left[\begin{array}{llllll}
0 & 0 & 0 & 0 & 0 & 0 \\
0 & 0 & 0 & 0 & 0 & 0 \\
0 & 0 & 0 & 0 & 0 & 0 \\
0 & 0 & 0 & 0 & 0 & 0 \\
0 & 0 & 0 & -\frac{p^{2}}{j} & 0 & 0 \\
0 & 0 & -\frac{p^{2}}{j} & 0 & 0 & 0
\end{array}\right]^{T}, \\
F_{1}=\left[\begin{array}{cccccc}
-a & -c & 0 & 0 & 0 & 0 \\
-c & -a & 0 & 0 & 0 & 0 \\
0 & 0 & 0 & 0 & 0 & 0 \\
0 & 0 & 0 & 0 & 0 & 0 \\
-h_{3} & 0 & 0 & 0 & 0 & 0 \\
0 & h_{3} & 0 & 0 & 0 & 0
\end{array}\right]^{T}, F_{2}=\left[\begin{array}{c}
h_{1} \\
h_{2} \\
0 \\
0 \\
0 \\
0
\end{array}\right],
\end{gathered}
$$




$$
\begin{aligned}
& F_{4}=\left[\begin{array}{cccccc}
0 & 0 & 0 & 0 & 0 & 0 \\
0 & 0 & 0 & 0 & 0 & 0 \\
0 & 0 & 0 & 0 & 0 & 0 \\
0 & 0 & 0 & 0 & 0 & 0 \\
1 & 0 & 0 & -j_{3} & j_{4} & 0 \\
0 & -1 & -j_{3} & 0 & 0 & j_{4}
\end{array}\right]^{T}, F_{3}=\left[\begin{array}{ccc}
0 & 0 \\
0 & 0 \\
-j_{1} & 0 \\
0 & -j_{2} \\
-j_{1} & 0 \\
0 & j_{2}
\end{array}\right] \\
& F_{4}=\left[\begin{array}{cccccc}
0 & 0 & 0 & 0 & 0 & 0 \\
0 & 0 & 0 & 0 & 0 & 0 \\
0 & 0 & 0 & 0 & 0 & 0 \\
0 & 0 & 0 & 0 & 0 & 0 \\
1 & 0 & 0 & -j_{3} & j_{4} & 0 \\
0 & -1 & -j_{3} & 0 & 0 & j_{4}
\end{array}\right]^{T}, F_{5}=\left[\begin{array}{cccccc}
0 & 0 & 0 & 0 & 0 & 1 \\
0 & 0 & 0 & 0 & 1 & 0 \\
0 & 0 & 0 & 0 & 0 & 0 \\
0 & 0 & 0 & 0 & 0 & 0 \\
0 & 0 & j_{3} & 0 & 0 & 0 \\
0 & 0 & 0 & -j_{3} & 0 & 0
\end{array}\right]^{T},
\end{aligned}
$$

\section{Simulation Results and Discussion}

The DFIG wind turbine controller verifies the efficiency of 1.5MW using Matlab software which has been executed with the $575 \mathrm{~V}_{\text {rms }}$ voltage at $50 \mathrm{~Hz}$, per unit system for the purpose of the simulation.

In this circumstance, wind speed varies with occurrence a step change between $10.1 \mathrm{~m} / \mathrm{s}$ and $10.5 \mathrm{~m} / \mathrm{s}$ is depicted in Fig. 4. The paper presents a state feedback controller for appropriate model of a DFIG wind generation unit to enhance the grid transient response of the machine. The results of the state variable of the wind turbine system are depicted shown in Fig. 5-Fig. 11. Fig. 5 shows the stator voltage response in $d q$ reference formation. It is examined that stator voltage decayed approximately $1.5 \mathrm{p}$.u at $1.2 \mathrm{~s}$ and after $1.2 \mathrm{~s}$ the fault is removed then recover the stator voltage to establish. The stator flux response in $d q$ frame is shown in Fig. 6, after $2.5 \mathrm{~s}$ very small deviation in the induction generator flux, it increases the network response. Wind turbine system is reduced by the interruption of the new generated component $\zeta_{s}$ in $d q$ frames shown in Fig. 7; it has been examined that the system becomes stable at $1.2 \mathrm{~s}$. The DFIG rotor speed is discussed in Eq. (15) that can be controlled at about 0.35 p.u shown in Fig. 8. The DC link voltage has been enhanced for the system voltages after $1.2 \mathrm{~s}$ on both rotor and grid side shown in Fig. 7, discussed in Eq. (23). Fig. 10 shows the reactive and real power response in the account of the reactive power in $1.2 \mathrm{~s}$ is about 0.62p.u and real power response about $0.75 \mathrm{p}$.u. The proposed method of the nonlinear dynamic model to

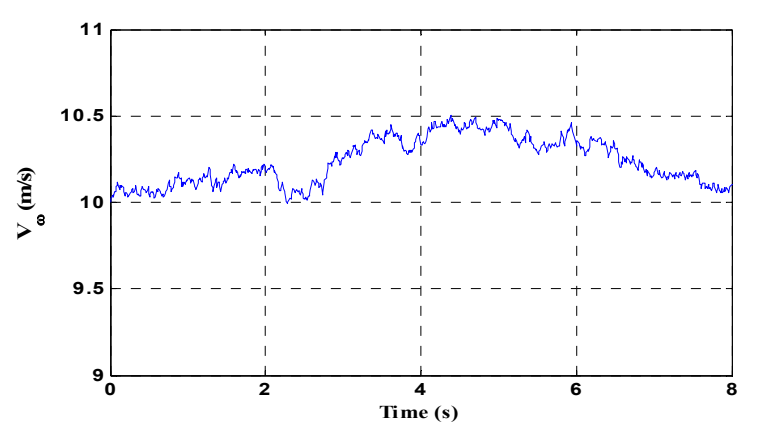

Fig. 4. Varation of wind speed versus time

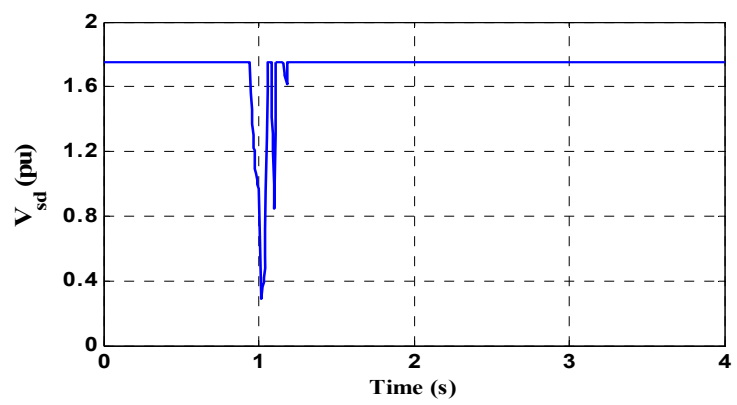

Fig. 5(a). Response of the stator voltage $V_{s d}$ versus time

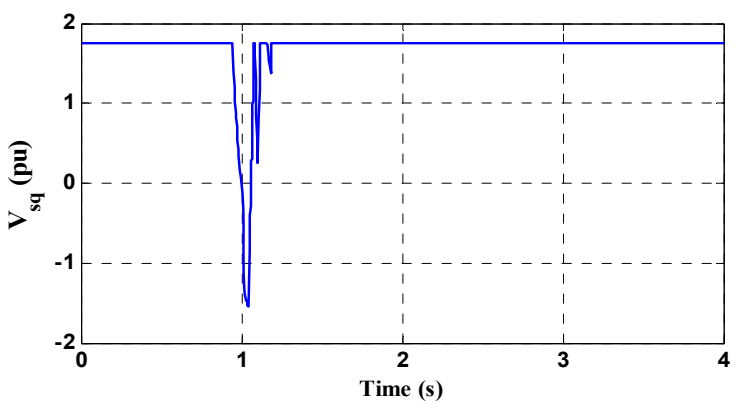

Fig. 5(b). Response of the stator voltage $V_{s q}$ versus time

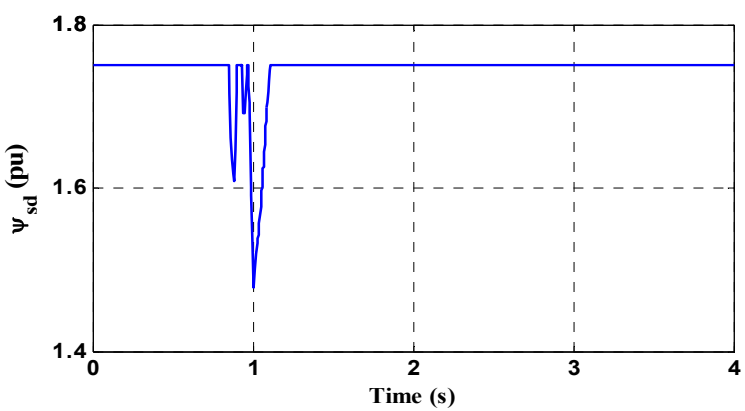

Fig. 6(a). Response of the stator flux $\psi_{s d}$ versus time

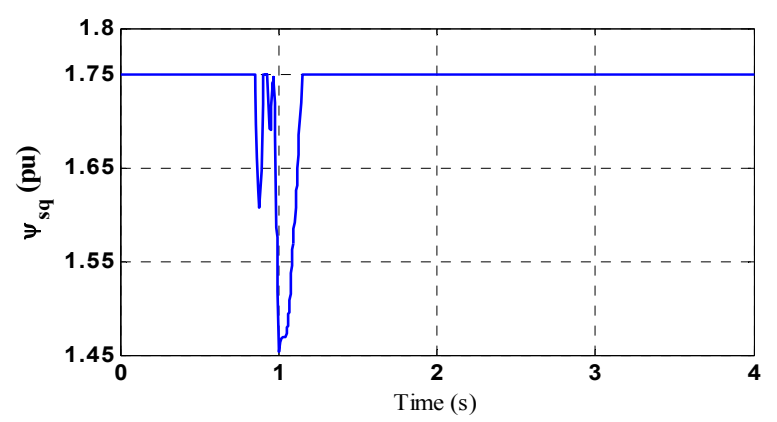

Fig. 6(b). Response of the stator flux $\psi_{s q}$ versus time

validate the efficiency of the simulation results has been performed. As originally, the performance of the dynamic system has been verified with the small change in real power. However, the real power varies with the small step change from $0.35 \mathrm{pu}$ to $0.75 \mathrm{pu}$, and at the same time reactive power set to zero $(\mathrm{pu})$. The real and reactive power of the time settlement is small and without overshoot of the zero steady state fault is shown in Fig 11. The dynamic 


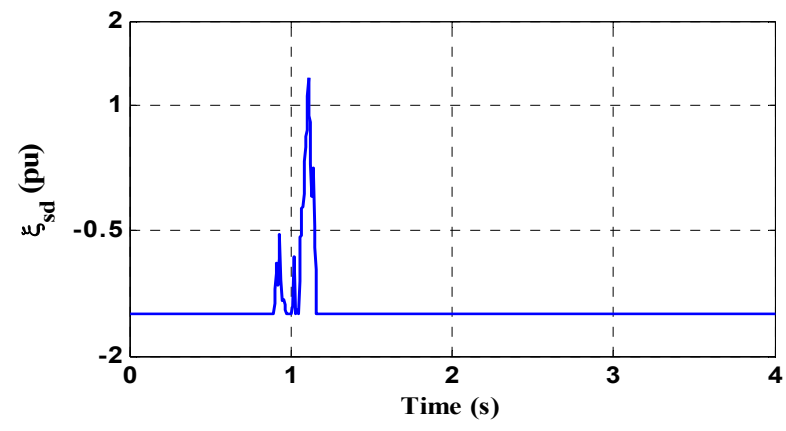

Fig. 7(a). Steady state $\zeta_{s d}$ response versus time

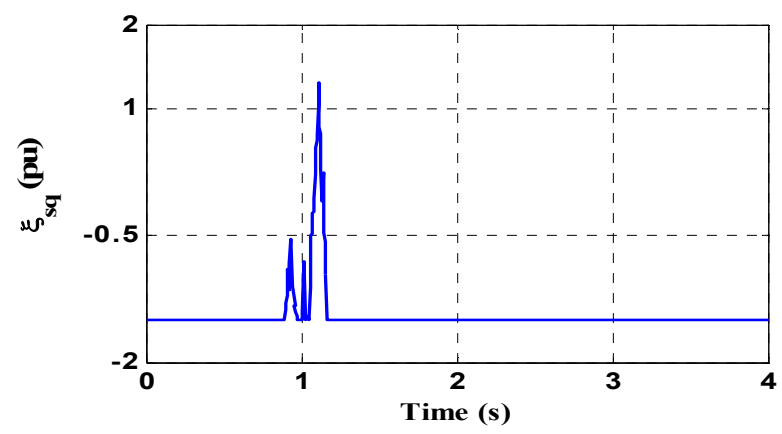

Fig. 7(b). Steady state $\zeta_{s q}$ response versus time

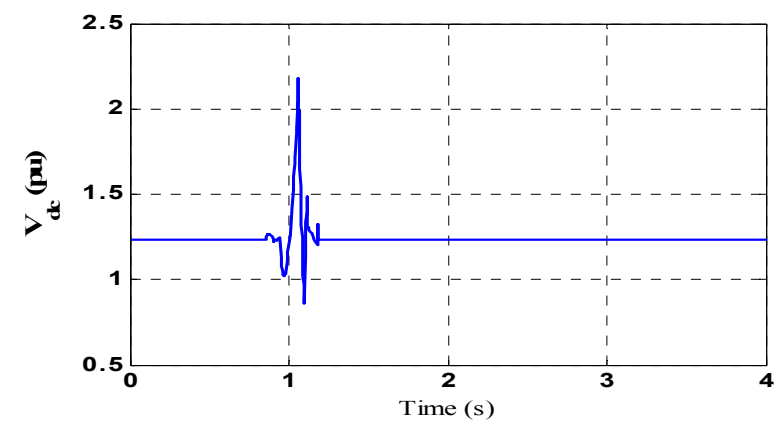

Fig. 8. Response of the DC voltage $V_{d c}$ versus time

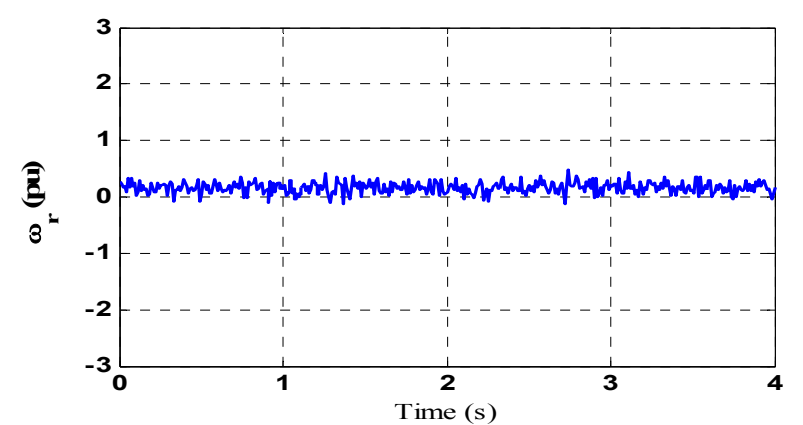

Fig. 9. Response of the angular rotor speed $\omega_{r}$ versus time

model response of real and reactive power reference signal perfectly track the proposed method as depicted in Fig. 11. It is verified that the proposed control method is robust than the conventional method in order to track the

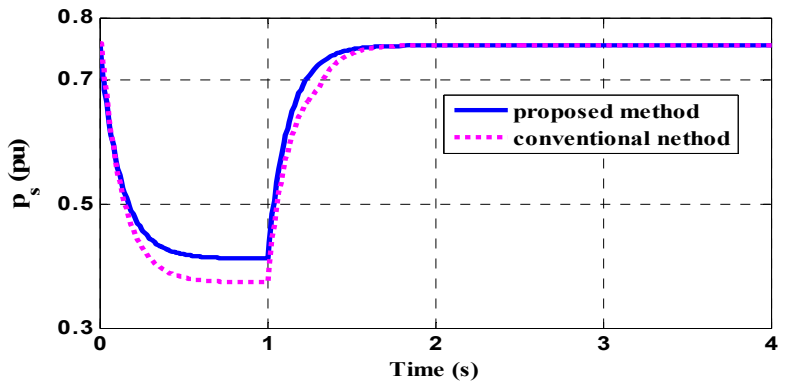

Fig. 10. Response to a active power imapct versus time

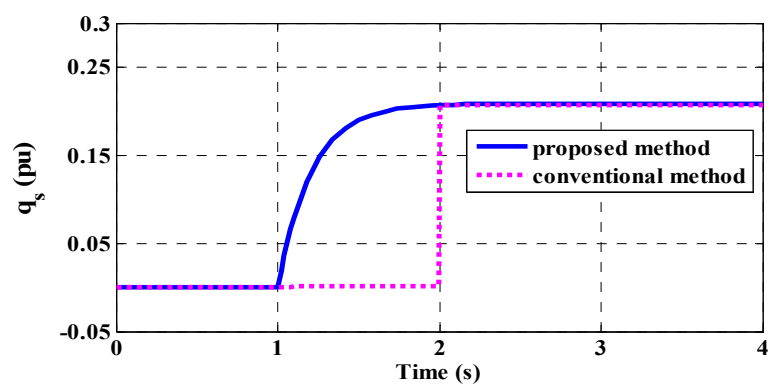

Fig. 11. Response to a reactive power imapct versus time

parameters of the reference signal as described in [19]. It is observed that the peak value of the stator current and DClink voltage is minimized and the disturbance of the system has been cleared.

\section{Conclusion and Future work}

The real and reactive power of the wind turbine is proposed using the feedback Linearization control strategy with a doubly fed induction generator. It can significantly improve the performance of the wind turbine system. A wind turbine dynamic model has been used to simulate the DFIG wind turbine under fault current characteristics of the generator, as well as an interpretation of its control and protection circuits. The results have been demonstrated that sag and overshot the real power and voltage from the wind farm can be reduced significantly after the removal of the disturbance. The feedback techniques improve the damping characteristics and the stability of the system. In addition to the dynamic response of the system modeling and the simulation result have been presented. It is important to examine the analytical characteristics of stability and can be more effective in the feedback technique to control the power system. In addition, the nonlinear dynamic model can be developed to make a simple controller design for DFIG wind turbine system under the light of grid voltage disturbance. Finally, it will be interesting to analytically model the relatively large and complex energy system scenario in order to demonstrate the applications of the feedback approach to such a complex control system. 


\section{Acknowledgements}

The authors would like to thank the Natural Science Foundation P R China under Grant No. 61374155, and the Specialized Research Fund for the Doctoral Program of Higher Education, $\mathrm{P} R$ China under Grant No. 20130073110030, for their fully support.

\section{Appendix A}

Table 1. 1.5 Mw DFIG wind turbine parameters

\begin{tabular}{c|c|c}
\hline Symbol & QUANTITY & Values \\
\hline$R_{s}$ & Stator Resistance & $1.4 \mathrm{~m} \Omega$ \\
\hline$R_{r}$ & Rotor Resistance & $0.99 \mathrm{~m} \Omega$ \\
\hline$l_{s}$ & Stator Inductance & $0.08998 \mathrm{mH}$ \\
\hline$l_{r}$ & Rotor Inductance & $0.08208 \mathrm{mH}$ \\
\hline$l_{m}$ & Mutual Inductance & $1.526 \mathrm{mH}$ \\
\hline$P$ & Pole Pairs & 3 \\
\hline$R_{f}$ & Grid Filter Resistance & $0.04 \Omega$ \\
\hline$l_{f}$ & Grid Filter Inductance & $0.001 \mathrm{H}$ \\
\hline$R_{L}$ & Load Resistance & $4.16 \Omega$ \\
\hline$l_{L}$ & Load Inductance & $4.093 \mathrm{H}$ \\
\hline$F$ & Frequency & $50 \mathrm{~Hz}$ \\
\hline$V_{\omega}$ & Wind Speed & $12 \mathrm{~m} / \mathrm{s}$ \\
\hline
\end{tabular}

\section{Appendix B}

$$
\begin{aligned}
& a_{d 1}+j a_{q 1}=\frac{Z_{f}}{l_{f}}+\frac{Z_{L}}{l_{s}^{\prime}}+\frac{Z_{L}}{l_{f}}, a_{d 2}+j a_{q 2}=\frac{Z_{l}}{l_{s}^{\prime} l_{r}}\left(R_{r}-\omega_{r} l_{r}\right) \\
& a_{d 3}+j a_{q 3}=\frac{2}{3}\left(\frac{R_{s} l_{r}+R_{r} l_{s}}{l_{s}^{\prime} l_{r}}+j \omega_{s l}-\frac{Z_{f}}{l_{f}}\right) Z_{l} \\
& a_{d 5}+j a_{q 5}=\frac{l_{m} Z_{L}}{l_{s}^{\prime} l_{r}}, \bar{V}_{g}=\frac{Z_{f}}{l_{f}} V_{l}-\frac{Z_{l}}{l_{f}} V_{g}, b_{d 1}+j b_{q 1}=j \omega_{e}, \\
& b_{d 2}+j b_{q 2}=\frac{2}{3} R_{s}, C_{d 1}+j C_{q 1}=1.5 \frac{1}{l_{s}^{\prime}} \\
& C_{d 2}+j C_{q 2}=\frac{3\left(R_{r}-\omega_{r} l_{r}\right)}{2 l_{s}^{\prime} l_{r}}, C_{d 4}+j C_{q 4}=1.5 \frac{l_{m}}{l_{s}^{\prime} l_{r}} ; \\
& C_{d 3}+j C_{q 3}=\frac{R_{s} l_{r}+R_{r} l_{s}}{l_{s}^{\prime} l_{r}}+j \omega_{s l}, a=\frac{Z_{d L}}{C\left|Z_{L}\right|^{2}}, c=\frac{Z_{l q}}{C\left|Z_{l}\right|^{2}} \text {; } \\
& j_{1}=1.5 \frac{1}{l_{m}}, j_{2}=\frac{2 l_{s}}{C l_{m}}, J_{3}=2 \omega_{e}, j_{4}=-1.2 R_{s} \text {; } \\
& h_{1}=\left\{\frac{Z_{d L} V_{d L}}{C\left|Z_{L}\right|^{2}}-\frac{Z_{q L} V_{q L}}{C\left|Z_{L}\right|^{2}}\right\}, h_{2}=\left\{\frac{Z_{d L} V_{q L}}{C\left|Z_{L}\right|^{2}}-\frac{Z_{q L} V_{d L}}{C\left|Z_{L}\right|^{2}}\right\} \text {, } \\
& h_{3}=\frac{2}{C}, l_{s}^{\prime}=\left(1-\frac{l_{m}^{2}}{l_{s} l_{r}}\right) l_{s}, \zeta_{s}=\frac{S_{s}}{V_{s}} \text {. }
\end{aligned}
$$

\section{References}

[1] R. Teodorescu, M. Liserre, and P. Rodriguez, "Grid Converters for Photovoltaic and Wind Power Systems," Sussex, U. K.: Wiley, 2011.

[2] F. Blaabjerg and K. Ma, "Future on power electronics for wind turbine systems," IEEE J. Emerg. Sel. Topics on Power Electron., vol. 1, no. 3, pp. 139-152, Sep. 2013.

[3] H. Polinder, J. A. Ferreira, B. B. Jensen, A. B. Abrahamsen, K. Atallah, and R. A. McMahon, "Trends in wind turbine generator systems," IEE J. Emerg. Sel. Topics on Power Electron., vol. 1, no. 3, pp. 174-185, Sep. 2013.

[4] G. Abad, G. Iwanski, J. López, L. Marroyo, and M. Rodríguez, "Doubly Fed Induction Machine: Modeling and Control for Wind Energy Generation Applications". Hoboken, NJ, USA: Wiley, 2011.

[5] R. Pena, J. C. Clare and G. M. Asher, "Doubly fed induction generator using back-to-back PWM converters and its application to variable speed windenergy generation," IEE Proc.-Elect. on Power Appl., vol. 143, no. 3, pp. 231-241, May 1996.

[6] L. Xu and P. Cartwright, "Direct active and reactive power control of DFIG for wind energy generation," IEEE Trans. On Energy Convers., vol. 21, no. 3, pp. 750-758, Sep. 2006.

[7] W. Qiao, W. Zhou, J. M. Aller and R. G. Harley, "Wind speed estimation based sensorless output maximization control for a wind turbine driving a DFIG," IEEE Trans. on Power Electron., vol. 23, no. 3, pp. 1156-1169, May 2008.

[8] H. Nian, Y. Song, P. Zhou and Y. He, "Improved direct power control of a wind turbine driven doubly fed induction generator during transient grid voltage unbalance," IEEE Trans. on Energy Convers., vol. 26, no. 3, pp. 976-986, Sept. 2011.

[9] H. Polinder, J. A. Ferreira, B. B. Jensen, A. B. Abrahamsen, K. Atallah, and R. A. McMahon, "Trends in wind turbine generator systems," IEEE J. Emering. Select. Topics on Power Electron, vol. 1, no. 3, pp. 174-185, Sept. 2013.

[10] D. Zhi, L. Xu and B. W. Williams, "Improved direct power control of grid-connected DC/AC converters," IEEE Trans. on Power Electron., vol. 24, no. 5, pp. 1280-1292, May 2009.

[11] S. Vazquez, J. A. Sanchez, J. M. Carrasco, J. I. Leon and E. Galvan,"A model-based direct power control for three-phase power converters," IEEE Trans. on Ind. Electron., vol. 55, no. 4, pp. 1647-1657, Apr. 2008.

[12] D. Zhi and L. Xu, "Direct power control of DFIG with constant switching frequency and improved transient performance," IEEE Trans. on Energy Convers. vol. 22, no. 1, pp. 110-118, Mar. 2007.

[13] P. Zhou, Y. He and D. Sun, "Improved direct power 
control of a DFIG based wind turbine during network unbalance," IEEE on Trans. Power Electron., vol. 24, no. 11, pp. 2465-2474, Nov. 2009.

[14] D. Zhi, L. Xu and B. W. Williams, "Model-based predictive direct power control of doubly fed induction generators," IEEE Trans. on Power Electron., vol. 25, no. 2, pp. 341-351, Feb. 2010.

[15] N. Amiri, S. M. Madani, T. A. Lipo, and H. A. Zarchi, "An improved direct decoupled power control of doubly fed induction machine without rotor position sensor and with robustness to parameter variation," IEEE Trans. on Energy Convers., vol. 27, no. 4, pp. 873-884, Dec. 2012.

[16] J. Hu, H. Nian, B. Hu, Y. He and Z. Q. Zhu, "Direct active and reactive power regulation of DFIG using sliding-mode control approach," IEEE Trans. on Energy Convers., vol. 25, no. 4, pp. 1028-1039, Dec. 2010.

[17] A. Balogun, O. Ojo and F. Okafor, "Decoupled direct control of natural and power variables of doubly fed induction generator for extended wind speed range using feedback linearization," IEEE J. Emerg. Sel. Topics on Power Electron., vol. 1, no. 4, pp. 226-237, Dec. 2013.

[18] P. Krause, O. Wasynczuk, S. Sudhoff and I. P. E. Society, Analysis of Electric Machinery and Drive Systems. Piscataway, NJ: IEEE, 2002.

[19] R. Esmaeil, A.Tabesh and M. Ebrahimi, "Dynamic model and control of DFIG wind energy systems based on power transfer matrix." IEEE Trans. on Power Delivery, vol. 27,no. 3,pp 1485-1493, July. 2012.

[20] S. Chen, N. Cheung, K. Wong and J. Wu, "Integral variable structure direct torque control of doubly fed induction generator," IET Renew. on Power Gen., vol. 5, no. 1, pp. 18-25, 2011.

[21] M. K. Bourdoulis and A.T. Alexandridis, "Direct power control of DFIG wind systems based on nonlinear modeling and analysis," IEEE J. Emerg. Sel. Topics on Power Electronics, vol. 2, no. 4, pp. 764-775, Dec. 2014.

[22] T. Ahmadreza and R. Iravani. "Multivariable dynamic model and robust control of a voltagesource converter for power system applications," IEEE Trans. on Power Delivery, vol. 24, no.1, pp. 462-471. Jan. 2009.

[23] R. Mohsen and M. Parniani. "Transient performance improvement of wind turbines with doubly fed induction generators using nonlinear control strategy," IEEE Trans. on Energy Conversion, vol. 25, no .2, pp. 514-525. June. 2010.

[24] M. Patel, "Wind and Solar Power Systems: Design, Analysis, and Operation". Boca Raton, FL: CRC, 2006.

[25] R. Mohsen and M. Parniani. "Grid-fault ride-through analysis and control of wind turbines with doubly fed induction generators." Electric Power Systems Research, vol. 80, no. 2, pp. 184-195, 2010.

[26] T. C. Yik, Yi Guo, and J. N. Jiang. "Nonlinear dualmode control of variable-speed wind turbines with doubly fed induction generators." IEEE Trans. on Control Systems Technology, vol. 19, no. 4, pp. 744756. 2011.

[27] D. Gan and O. Olorunfemi. "Efficiency optimizing control of induction motor using natural variables." IEEE Trans. on Industrial Electronics, vol. 53, no.6, pp 1791-1798, Dec. 2006.

[28] Z. Tao and B. François. "Energy management and power control of a hybrid active wind generator for distributed power generation and grid integration." IEEE Trans. on Industrial Electronics, vol. 58, no. 1, pp. 95-104, Jan. 2011.

[29] X. Kaigui and R. Billinton. "Determination of the optimum capacity and type of wind turbine generators in a power system considering reliability and cost." IEEE Trans on Energy Conversion, vol. 26, no. 1, pp. 227-234, March. 2011.

[30] P. Rodríguez, et al. "Multiresonant frequency-locked loop for grid synchronization of power converters under distorted grid conditions." IEEE Trans. on Industrial Electronics, vol. 58, no. 1, pp. 127-138, Jan. 2011.

[31] Baloch MH, Wang J, Kaloi GS. Stability and nonlinear controller analysis of wind energy conversion system with random wind speed. International Journal of Electrical Power \& Energy Systems. 2016; 79:7583.

[32] M. Mansour, S. M. Islam, and M. A Masoum. "Enhanced hysteresis -based current regulators in vector control of DFIG wind turbines." IEEE Trans. on Power Electronics, vol. 26, no .1, pp. 223-234. Jan. 2011.

[33] T. Etienne, S. Atayde, and A. Chandra. "Comparative study of control strategies for the doubly fed induction generator in wind energy conversion systems: A DSP-based implementation approach." IEEE Trans. on Sustainable Energy, vol. 2, no. 3, pp. 288-299, July. 2011.

[34] D. Rajib and V. T. Ranganathan. "Direct power control of grid-connected wound rotor induction machine without rotor position sensors." IEEE Trans. on Power Electronics, vol. 16, no. 3, pp. 390-399, May. 2001.

[35] J. Yang, J. Fletcher and J. O'Reilly, “A seriesdynamic-resistor-based converter protection scheme for doubly-fed induction generator during various fault conditions," IEEE Trans. on Energy Conversion, vol. 25, no. 2, pp. 422-432, Jun. 2010.

[36] Baloch MH, Wang J, Kaloi GS. (0043) Modeling and controller design for wind energy conversion system based on a cage induction generator using turbulence speed. Journal of Power Technologies. 2016. 


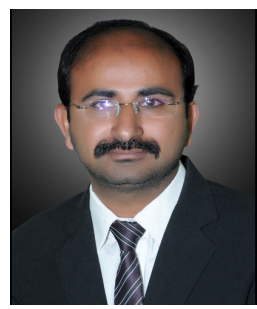

Ghulam Sarwar Kaloi received the B. E and M. E degrees in Electrical Power Engineering from Mehran University of Engineering and Technology, Jamshoro and Quaid-e-Awam University of Engineering Science and Technology, Nawabshah, Sindh Pakistan in 2006 and 2013, respectively. He was a Lecturer in the Department of Electrical Engineering in University College of Engineering \& Technology, The Islamia University of Bahawalpur, Punjab Pakistan from 2010 to 2014 . He is currently a research scholar in the Department of Electrical Engineering, Shanghai Jiao tong University, P R China. His research interest includes nonlinear control, power system stability and wind power system.

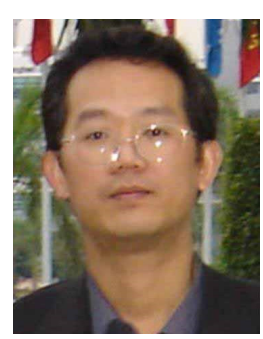

Jie Wang (M'02) received the B. E., M. E., and $\mathrm{Ph}$. D. degrees from Southeast University, Nanjing, China, North China Electric Power University, Baoding, China and North Eastern University, Shenyang, P R China, in 1982, 1991, and 1998, respectively. He was a Postdoctoral Researcher with Shanghai Jiao Tong University, Shanghai, P R China. He is currently a Professor with the Shanghai Jiao Tong University. His research interest includes nonlinear control theory and its application in power systems, complex dynamic system and wind power system.

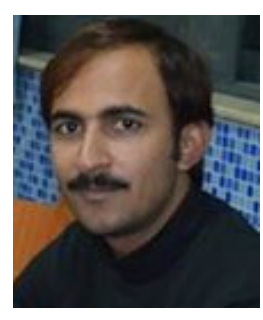

Mazhar Hussain Baloch received the B. E and M. E degrees in Electrical Power Engineering from Mehran University of Engineering and Technology, Jamshoro, Sindh Pakistan, in 2008 and 2013, respectively. He was a Lecturer in the Department of Electrical Engineering in University College of Engineering \& Technology, The Islamia University of Bahawalpur, Punjab Pakistan from 2010 to 2014. He is currently a research scholar in the Department of Electrical Engineering, Shanghai Jiao tong University, P R China. Mr. Hussain is an Assistant Professor at Mehran University of Engineering and Technology, Jamshoro, Khairpur Mir's Campus. His research interest includes nonlinear control theory \& its application in power systems, induction machines, complex dynamic system and wind power system. 